\title{
GIẢI PHÁP TRONG PHÁT TRIỂN CHẤT LƯợNG NGUỒN NHÂN LỰC TRONG LĨNH VỰC MÔI TRƯờNG
}

\author{
Phạm Thị Tố Oanh ${ }^{1}$
}

Tóm tắt: Việt Nam là quốc gia chịu nhiều tác động của biến đổi khi hậu, ô nhiễm môi truờng, đòi hỏi cần có nguồn nhân lực đạt chất lượng để giải quyết vấn đề này ở cấp trung ương, tỉnh, huyện, xã. Đội ngũ cán bộ, giáo viên, giảng viên, nghiên cưu viên được đào tạo chuyên ngành môi truờng chiếm tỷ lệ nhỏ trên tổng số và đa số chura triển khai thực tiễn. Đối tượng đào tạo chủ yếu tiếp cận lý thuyết, it thực hành và tỷ lệ làm đúng chuyên ngành không cao; doanh nghiẹp hay co sở sản xuất đánh giá không cao về chất lượng đào tạo, nhiều người không thể triển khai công việc. Giải pháp: tập trung quy hoạch các trương, co sở đào tạo một cách hệ thống; kết hợp, phối hợp giữa co* sở sản xuất, doanh nghiệp với các co sở đào tạo; lý thuyết và thực tiễn; kế hoạch đào tạo, bồi duỡng giáo viên, giảng viên và nghiên cưu viên; cải tiến cách tiếp cận lấy người học làm trung tâm mà lấy nội dung đào tạo làm trung tâm; phát huy chủ động, sáng tạo; có chính sách khuyến khích, thu hút nhân tài.

Từ khóa: Nguồn nhân lục, đào tạo, chất lượng trong lĩnh vục môi trường.

Ban biên tập nhận bài: 11/12/2019 Ngày phản biện xong: 12/12/2019 Ngày đăng bài: 20/12/2019

\section{Mở đầu}

Việt Nam đang trong quá trình công nghiệp hóa, hiện đại hóa đất nước, phát triển theo hướng mở cửa, hội nhập quốc tế. Cùng với sự phát triển của nền kinh tế đất nước, ngành tài nguyên môi trường nói chung, lĩnh vực môi trường nói riêng cũng ngày càng lớn mạnh cả về quy mô tổ chức bộ máy quản lý nhà nước và nguồn nhân lực, nhằm đáp ứng yêu cầu thực tiễn. Tuy nhiên, bên cạnh những thành tựu đạt được, nhiều vấn đề cấp thiết về môi trường nảy sinh đòi hỏi ngành môi trường phải có chiến lược phát triển phù hợp, có tầm nhìn, đánh giá đúng xu thế phát triển kinh tế - xã hội, đưa ra chiến lược phát triển của ngành, đó là: mô hình quản lý, phương thức quản lý, khả năng phát triển, đặc biệt có kế hoạch cụ thể trong xây dựng nguồn nhân lực đủ về số lượng, mạnh về chất lượng [8].

Bên cạnh phải đối mặt với những vấn đề môi trường toàn cầu thì Việt Nam cũng đang gặp khó khăn trong việc giải quyết và thích ứng với những vấn đề môi trường nội tại như: Tác động của biến đổi khí hậu; suy thoái và ô nhiễm môi trường đất, nước, không khí; suy giảm đa dạng sinh học; suy giảm chất lượng môi trường sống của cộng đồng [3].

Nguồn nhân lực làm công tác quản lý nhà nước về bảo vệ môi trường hiện chưa đáp ứng được yêu cầu nhiệm vụ đặt ra [2]. Ở Trung ương, một số lĩnh vực còn thiếu đội ngũ công chức, viên chức có trình độ cao, chuyên môn sâu. Đối với địa phương, đội ngũ công chức, viên chức thực hiện nhiệm vụ bảo vệ môi trường, đặc biệt trong các lĩnh vực đánh giá tác động môi trường, bảo tồn đa dạng sinh học, kinh tế môi trường... đang thiếu về số lượng, yếu về chất lượng, cơ cấu đội ngũ cán bộ bố trí chưa hợp lý, phần lớn số công chức, viên chức được đào tạo về các chuyên ngành kỹ thuật, thiếu kỹ năng quản lý [9].

Trong kết quả tổng hợp thông tin, xây dựng cơ sở dữ liệu, nghiên cứu, đánh giá 15 năm qua, đội ngũ công chức, viên chức chưa được chuyên nghiệp, chuẩn hóa, hiện đại hóa. Do vậy, cần phải có những giải pháp để đào tạo và phát triển nguồn nhân lực quản lý và triển khai ngành môi trường trong giai đoạn hiện nay.

\section{Phương pháp nghiên cứu}

${ }^{1}$ Liên minh Hợp tác xã Việt Nam

Email:oanhpt@vca.org.vn 
Để đạt được kết quả nghiên cứu, chúng tôi sử dụng phương pháp tổng hợp thông tin dữ liệu liên quan thực trạng, hệ thống quản lý môi trường, những công trình nghiên cứu, các sách, báo và các tạp chí khoa học từ thực trạng đào tạo tới sản phẩm đào tạo hay từ nhu cầu các cơ quan, doanh nghiệp với việc tiếp nhận sản phẩm đào tạo; số liệu thống kê; đặc biệt phân tích những mối liên hệ, tính thống nhất hay mâu thuẫn của các vấn đề trong công tác đào tạo với nhu cầu thực tiễn; phương pháp tổng hợp, phương pháp chuyên gia. Đó là cơ sở quan trọng để đề xuất phương án, giải pháp trong thời gian tới nhằm từng bước giải quyết các vấn đề cấp thiết hiện nay về công tác đào tạo nguồn nhân lực trong lĩnh vực bảo vệ môi trường.

\section{Kết quả và thảo luận}

\subsection{Phân tích kinh nghiệm một số nước và thục tiễn ở Việt Nam}

Một số nước đã xây dựng chiến lược phát triển nguồn nhân lực cho đất nước nói chung: Singapore, Hàn Quốc, Trung Quốc, Nhật Bản,.... Tuy nhiên, không có chiến lược cụ thể phát triển nguồn nhân lực riêng cho lĩnh vực môi trường. Đa số trong chiến lược đều tập trung nội dung tạo dựng tri thức và nguồn nhân lực để trở thành động lực cho tăng trưởng, coi đó là chính sách quốc gia quan trọng hàng đầu để đạt được những mục tiêu về phát triển kinh tế - xã hội và đạt được thắng lợi trong quá trình toàn cầu hóa và hội nhập quốc tế. Tùy theo đặc thù và tình hình của mỗi quốc gia, nguồn nhân lực môi trường là một trong những lực lượng quan trọng của việc phát triển nguồn nhân lực quốc gia. Giải pháp đề ra là tăng cường hợp tác giữa các doanh nghiệp, trường đại học, cơ sở nghiên cứu, trong đó các trường đại học phải là trung tâm; nâng cao trình độ sử dụng và quản lý nguổn nhân lực: nâng cao tính chuyên nghiệp của nguồn nhân lực trong khu vực công, trước hết là tăng cường năng lực hoạch định chính sách, ra quyết định trong xã hội tri thức, chính phủ tri thức...

Ở một số nước, các doanh nghiệp sau khi ký kết với các trường đại học, cơ sở nghiên cứu sẽ đặt hàng số lượng sinh viên tốt nghiệp họ cần, yêu cầu về chất lượng thế nào và chi trả tiền đào tạo và sản phẩm nghiên cứu cụ thể, có chính sách thu hút nhân tài. Chính vì thế, các doanh nghiệp có được những sản phẩm sau đào tạo và sản phẩm nghiên cứu theo yêu cầu. Khi những sản phẩm nghiên cứu tốt, nhân lực làm việc tốt, doanh nghiệp phát triển và có tính bền vững cao, đáp ứng chiến lược phát triển ngành, lĩnh vực cụ thể.

Trung ương Đảng và Quốc vụ viện Trung Quốc đã ban hành Quyết định về tăng cường công tác bồi dưỡng nhân tài (2003) nhằm thực hiện mục tiêu xây dựng toàn diện xã hội được đề ra trong Đại hội XVI của Đảng Cộng sản Trung Quốc. Chiến lược về bồi dưỡng nhân tài đặt trọng tâm xây dựng đội ngũ nhân tài ở vị trí quan trọng (gồm cán bộ lãnh đạo trung, cao cấp, nhà doanh nghiệp ưu tú và các chuyên gia cao cấp trên các lĩnh vực trọng điểm, trong đó có môi trường); khai thác tổng thể nguồn lực nhân tài, thực hiện phát triển hài hòa công tác nhân tài; giữ vững nguyên tắc Đảng quản lý nhân tài, nỗ lực mở ra cục diện mới trong công tác nhân tài: chú trọng động viên và tổ chức mọi lực lượng xã hội, tăng cường đầu tư, hoàn thiện pháp chế, ưu việt hóa môi trường.

Singapore quan tâm đặc biệt cho công tác đào tạo, bồi dưỡng đội ngũ công chức, coi đó là giải pháp cơ bản nhất để xây dựng công vụ có hiệu quả. Theo quy định, mỗi cán bộ, công chức bắt buộc phải được bồi dưỡng 100 giờ/năm; mỗi công chức phải tự đề ra chương trình học tập cho mình. Để khuyến khích việc tự đào tạo, Chính phủ quy định hỗ trợ $50 \%$ chi phí cho những người tự học để phục vụ cho công việc đang đảm trách. Các hình thức đào tạo, bồi dưỡng là: Đào tạo ban đầu, đào tạo nâng cao, đào tạo mở rộng và đào tạo bổ sung. Các hình thức này có liên quan chặt chẽ tới cuộc đời của công chức. Đào tạo được tổ chức theo các hình thức chính quy hoặc tại chức. Tùy theo yêu cầu của từng loại đối tượng, có thể có những phần hợp nhất giữa một vài công đoạn, đáp ứng tốt hơn nhu cầu cá nhân của công chức. Các cơ sở đào tạo của Singapore bao gồm Học viện Công vụ và Viện Quản lý Singapore. Chính phủ Singapore còn trao quyền tự 
quyết định cho các bộ, ngành lựa chọn nơi đào tạo công chức, không nhất thiết phải vào trường công vụ.

Ở Việt Nam, Thủ tướng Chính phủ đã phê duyệt Đề án kiện toàn tổ chức bộ máy quản lý nhà nước về $\mathrm{BVMT}$ và tăng cường năng lực cho đội ngũ cán bộ quản lý môi trường từ Trung ương đến địa phương giai đoạn 2016 - 2020, tầm nhìn đến năm 2030 tại Quyết định số 1169/QĐTTg ngày 10/8/2017 [10].

Hiện nay, Việt Nam đang hoàn thiện đề án tăng cường năng lực hệ thống tổ chức và đội ngũ công chức, viên chức ngành tài nguyên và môi trường đến năm 2030 nhằm mục tiêu kiện toàn hệ thống tổ chức, tăng cường năng lực đội ngũ công chức, viên chức, người lao động thuộc ngành tài nguyên và môi trường từ Trung ương đến địa phương nhằm nâng cao hiệu lực, hiệu quả quản lý nhà nước về tài nguyên và môi trường phát triển ngành tài nguyên và môi trường ngày càng chính quy, hiện đại, thúc đẩy quá trình công nghiệp hóa, hiện đại hóa, hội nhập quốc tế và bảo đảm sự phát triển bền vững của đất nước [7].

\subsection{Hệ thống các trưòng đào tạo, Viện nghiên cứu, Trung tâm về môi trưòng}

* Truoòng đào tạo

Đối với đào tạo chuyên ngành môi trường, ở Việt Nam có 2 trường Đại học Tài nguyên và Môi trường (Hà Nội và thành phố Hồ Chí Minh) đào tạo chính quy hệ đại học và sau đại học chuyên ngành về môi trường, quản lý và xử lý môi trường.

Bên cạnh đó có 94 trường Đại học có khoa chuyên môn hoặc chuyên ngành đào tạo môi trường: Trường Đại học Khoa học Tự nhiên (Hà Nội và thành phố Hồ Chí Minh), Đại học Bách khoa (Hà Nội và thành phố Hồ Chí Minh), Đại học Thủy lợi, Đại học Xây dựng, Đại học Kiến trúc, trường Đại học Kinh tế quốc dân, Đại học Lâm nghiệp, Học viện nông nghiệp, Đại học mỏ địa chất, Đại học Khoa học và Công nghệ Hà Nội, Đại học công nghiệp (Hà Nội, thành phố Hồ Chí Minh); Đại học Cần Thơ, Đại học Kinh tế Nghệ An, Đại học Thái Nguyên,...
Hiện cả nước có 46 trường cao đẳng có đào tạo về môi trường: Trường cao đẳng tài nguyên và môi trường, cao đẳng nông nghiệp và phát triển nông thôn Bắc Bộ, cao đẳng tài nguyên và môi trường miền Trung, cao đẳng công nghệ kinh tế và thủy lợi miền Trung, cao đẳng kinh tế -kỹ thuật-đại học Thái Nguyên.

Về trường bồi dưỡng cán bộ quản lý môi trường, Việt Nam có một trường đào tạo bồi dưỡng cán bộ tài nguyên môi trường (Hà Nội).

*Viện nghiên cúu

Hiện cả nước có 42 Viện nghiên cứu có nghiên cứu về môi trường: Viện Công nghệ Môi trường, thuộc Viện Hàn lâm khoa học Việt Nam (Hà Nội), Viện Tài nguyên và môi trường biển (Hải Phòng), Viện Tài nguyên và Môi trường Đại học Quốc gia Hà Nội, Viện Môi trường và Tài nguyên (thành phố Hồ Chí Minh), Viện nghiên cứu cấp thoát nước và môi trường -Hội cấp thoát nước Việt Nam (Hà Nội), Viện Khoa học Môi trường - Tổng cục Môi trường, Viện khoa học khí tượng thủy văn và biến đổi khí hậu (Hà Nội), Viện phát triển kinh tế hợp tác - Liên minh HTX Việt Nam,...

* Trung tâm

Nhiều Bộ, ngành, tỉnh, thành phố có các trung tâm nghiên cứu, triển khai về môi trường. Cả nước hiện có 471 Trung tâm có triển khai lĩnh vực môi trường và liên quan môi trường : Trung tâm môi trường và sản xuất sạch (Bộ công thương), Trung tâm khoa học và công nghệ môi trường (Liên minh HTX Việt Nam), Trung tâm dịch vụ khoa học kỹ thuật sức khỏe và môi trường (Bộ $\mathrm{y}$ tế), Trung tâm thông tin - khoa học công nghệ môi trường (Bộ quốc phòng), Trung tâm Hành động quốc gia khắc phục hậu quả chất độc hóa học và môi trường (Bộ quốc phòng),... Các đơn vị này đều có nhu cầu tuyển dụng về chuyên ngành kỹ thuật môi trường là chủ yếu.

\subsection{Bộ máy quản lý nhà nước}

Hệ thống quản lý: Bộ Tài nguyên và Môi trường; Sở Tài nguyên và Môi trường các tỉnh, thành phố trực thuộc Trung ương trên cả nước; Phòng Tài nguyên và Môi trường các quận, huyện, thị xã, thành phố thuộc tỉnh, thành phố 
trực thuộc Trung ương; cán bộ địa chính - xây dựng - đô thị và môi trường (đối với phường, thị trấn) hoặc địa chính - nông nghiệp - xây dựng và môi trường (đối với xã).

Hiện nay, tại 63 tỉnh, thành phố đều có hệ thống Sở Tài nguyên và Môi trường, với số lượng cán bộ quản lý là 12.258 cán bộ. Cấp huyện có các phòng Tài nguyên và Môi trường thuộc UBND cấp huyện, với 45.251 cán bộ. Cấp xã có cán bộ tài nguyên và môi trường, với 10.102 cán bộ.

Theo Bộ Tài Nguyên và Môi trường, đội ngũ cán bộ, công chức, viên chức, người lao động trong toàn ngành môi trường hiện nay có gần 50.000 người. Tuy nhiên, nhu cầu nguồn nhân lực được đào tạo các chuyên ngành tài nguyên và môi trường cần bổ sung lực lượng, trong đó tập trung tăng cường cho một số lĩnh vực như đất đai, tài nguyên nước, khí tượng thủy văn, đo đạc và bản đồ, địa chất khoáng sản và một số chuyên ngành mới...[6].

Ngành tài nguyên và môi trường là một ngành đa lĩnh vực, được hình thành trên cơ sở hợp nhất nhiều lĩnh vực quản lý nhà nước. Vấn đề quản lý tài nguyên môi trường đang được xã hội quan tâm, cơ hội việc làm khá lớn và có thể làm ở nhiều cơ quan, đơn vị khác nhau. Hiện nay đang thực hiện chức năng, nhiệm vụ quản lý nhà nước trên 07 lĩnh vực, bao gồm: đất đai; tài nguyên nước; tài nguyên khoáng sản, địa chất; môi trường; khí tượng thủy văn và biến đổi khí hậu; đo đạc và bản đồ; quản lý tổng hợp và thống nhất về biển và hải đảo. Đây là những lĩnh vực có tính phức tạp, nhạy cảm, liên quan trực tiếp đến quyền lợi của nhân dân, tổ chức, doanh nghiệp, có tác động lớn đến bảo đảm an ninh, quốc phòng, sự phát triển kinh tế - xã hội và sự phát triển bền vững của đất nước; gắn liền với công tác điều tra cơ bản, nghiên cứu, phát triển khoa học và công nghệ [1].

\subsection{Doanh nghiẹp}

Hiện hàng nghìn doanh nghiệp trong và ngoài nước hoạt động trên nhiều lĩnh vực là điều kiện thu hút nguồn nhân lực về môi trường. Các công ty, nhà máy, doanh nghiệp đều cần và đều được các cơ quan chức năng yêu cầu về quản lý, phòng ngừa, giảm thiểu và xử lý ô nhiễm môi trường. Trong xu hướng thị trường, đất nước càng phát triển thì nhu cầu nguồn nhân lực về công tác môi trường càng nhiều, chủ yếu tuyển dụng kỹ sư môi trường.

\subsection{Về chất lượng của đội ngũ chuyên gia}

Trong những năm qua, cùng với sự phát triển của ngành tài nguyên và môi trường, đội ngũ chuyên gia, cán bộ khoa học và công nghệ đã phát triển nhanh về số lượng, trưởng thành một bước về chất lượng, thích nghi dần với nền kinh tế thị trường và có những đóng góp đáng kể trong sự nghiệp phát triển của ngành tài nguyên và môi trường nói riêng, phát triển kinh tế - xã hội nói chung. Một số lượng đáng kể chuyên gia, cán bộ khoa học và công nghệ có trình độ chuyên môn, công nghệ và ngoại ngữ tốt đã được thu hút về công tác tại Bộ Tài nguyên và Môi trường. Lực lượng này đã tham gia tích cực, hiệu quả vào việc nghiên cứu và giải quyết một số vấn đề lớn, quan trọng về khoa học và công nghệ và phát triển các lĩnh vực của ngành tài nguyên và môi trường. Đây là nguồn nhân lực rất quan trọng đối với Bộ Tài nguyên và Môi trường [4].

Nhìn chung, đội ngũ chuyên gia, cán bộ khoa học và công nghệ của Bộ, của ngành tài nguyên và môi trường đã có nhiều đóng góp quan trọng, thiết thực trong việc xây dựng những luận cứ khoa học đưa ra các quyết sách, hoạch định chính sách, pháp luật, quy hoạch, kế hoạch phát triển ngành; xây dựng định hướng nghiên cứu phát triển công nghệ và trực tiếp thực hiện các nhiệm vụ nghiên cứu quan trọng góp phần trong sự nghiệp phát triển của Bộ, ngành. Một số cán bộ đầu ngành còn tham gia vào công tác quản lý, lãnh đạo ở các đơn vị của Bộ, của ngành ở Trung ương và địa phương. Đội ngũ này đã luôn phát huy tốt vai trò và khả năng của mình, không ngừng nâng cao hiệu quả lãnh đạo, quản lý, điều hành, góp phần quan trọng vào sự đổi mới hoạt động của của Bộ, của ngành.

Tuy nhiên, đội ngũ chuyên gia, cán bộ khoa học và công nghệ của Bộ còn bất cập cả về số lượng cũng như chất lượng, cơ cấu ngành nghề. 
Trong tình hình hiện nay, mặc dù các Nghị quyết của Đảng, các văn bản pháp luật của Nhà nước đã nêu rõ sự quan tâm, đề cao vai trò của nhân tài khoa học và đã có những quy định về việc trọng dụng được đào tạo chuyên ngành gần với môi trường như hóa học, sinh học, địa lý, địa chất,...

Theo số liệu thống kê bước đầu cho thấy, tỷ lệ cán bộ hoạt động khoa học và công nghệ, nhưng chưa được cụ thể hóa để thực sự đào tạo, bồi dưỡng, trọng dụng, đãi ngộ, tôn vinh đội ngũ cán bộ khoa học và công nghệ; tạo môi trường thuận lợi, điều kiện vật chất để đội ngũ cán bộ khoa học và công nghệ phát triển bằng tài năng và hưởng lợi ích xứng đáng với giá trị lao động sáng tạo của mình; đây là một vấn đề cấp bách cần được giải quyết kịp thời [5].

\subsection{Nghiên cúu về giáo viên, giảng viên,}

\section{nghiên cứu viên}

Trong các trường đào tạo có đội ngũ các giáo viên, giảng viên. Trong các đơn vị quản lý, các đơn vị tổ chức triển khai có đội ngũ nghiên cứu viên. Qua nghiên cứu thực tiễn và điều tra thống kê sơ bộ thí điểm chọn mục phục vụ công tác đào tạo chuyên ngành môi trường của khoa tài nguyên và môi trường, trường Đại học Khoa học, Đại học Thái Nguyên vào tháng 7/2018 tại 18 trường đào tạo nêu trên, có thể một phần các giảng viên, giáo viên và nghiên cứu viên được đào tạo chuyên ngành môi trường, một số lớn hiện không được đào tạo chính quy về môi trường, một số giáo viên, giảng viên được đào tạo đúng chuyên ngành môi trường chỉ chiếm $33,2 \%$, trong khi các lĩnh vực liên quan và khác chiếm tỷ lệ cao $66,8 \%$.

Bảng 1. Tỷ lệ các chuyên ngành đào tạo của giáo viên, giảng viên và nghiên cứu viên (Kết quả điều tra so bộ tù̀ Khoa tài nguyên và môi trường, Đại học Thái Nguyên, 7/2018)

\begin{tabular}{lccccc}
\hline \multicolumn{1}{c}{ Chuyên ngành đào tạo } & Môi trường & Hóa học & $\begin{array}{c}\text { Sinh } \\
\text { học }\end{array}$ & $\begin{array}{c}\text { Địa lý, } \\
\text { địa chất }\end{array}$ & Khác \\
\hline $\begin{array}{l}\text { Giáo viên, giảng viên được đào tạo theo } \\
\text { chuyên ngành }\end{array}$ & $33,2 \%$ & $21,5 \%$ & $18,7 \%$ & $12,6 \%$ & $14 \%$ \\
$\begin{array}{l}\text { Nghiên cứu viên được đào tạo theo } \\
\text { chuyên ngành }\end{array}$ & $29,8 \%$ & $23,5 \%$ & $19,1 \%$ & $13,1 \%$ & $14,5 \%$ \\
$\begin{array}{l}\text { Giáo viên, giảng viên được đào tạo thực } \\
\text { tiễn/Tổng sổ giáo viên, giảng viên được }\end{array}$ & $41,2 \%$ & $47,2 \%$ & $37,9 \%$ & $23,5 \%$ & $13,4 \%$ \\
đào tạo theo chuyên ngành & & & & & \\
\hline
\end{tabular}

Các nghiên cứu viên được đào tạo theo chuyên ngành môi trường chiếm $29,8 \%$ trong khi các lĩnh vực liên quan và khác chiếm tỷ lệ $70,2 \%$.

Trong đó, tỷ lệ các giáo viên được đào tạo chuyên ngành môi trường đã qua triển khai thực tiễn cơ sở, nắm được các phương thức, tổ chức, những công nghệ, kỹ thuật ứng dụng trong thực tiễn chỉ chiếm $41,2 \%$ tổng số giáo viên, giảng viên có chuyên ngành đào tạo chính về môi trường. Các giáo viên ở các lĩnh vực chuyên môn khác nhưng hiện giảng dạy về môi trường đa số cũng ít qua thực tiễn cơ sở. Ví như trong lĩnh vực khác chỉ có $13,4 \%$ giảng viên, giáo viên đã nắm vững phương thức triển khai các vấn đề môi trường trong thực tiễn.

Điều này cho thấy chuyên ngành đào tạo và tính thực tiễn của các giáo viên, giảng viên ảnh hưởng không ít đến công tác đào tạo nguồn nhân lực.

Bên cạnh đó, cả nước chỉ có duy nhất một trường đào tạo bồi dưỡng cán bộ môi trường. Tuy nhiên, trường này mở nhiều lớp bồi dưỡng cán bộ cho cán bộ cấp tỉnh, huyện, rất hiếm có lớp bồi dưỡng chuyên sâu cho các giáo viên, giảng viên. Vì thế, việc đào tạo bồi dưỡng cho giáo viên, giảng viên không được thường xuyên, liên tục, kiến thức không được cập nhật; phương pháp giảng dạy không được đổi mới, giáo viên và giảng viên không có điều kiện học tập thực tiễn tại các cơ sở.

Đa số các giáo viên, giảng viên trong quá trình giảng dạy tự hoàn thiện kiến thức, học hỏi đồng nghiệp, tự liên hệ các đơn vị, triển khai các chương trình, dự án cụ thể để hoàn thiện tính 
thực tiễn và tiếp tục bổ sung kiến thức mới, hỗ trợ tích cực cho công tác giảng dạy. Tuy nhiên, không phải tất cả các giáo viên và giảng viên có điều kiện để tiếp cận. Nhiều giáo viên chỉ với kiến thức có sẵn để có thể giảng dạy sinh viên dựa chính vào hệ thống giáo trình, tài liệu biên soạn chuyên khảo hay tham khảo.

Các nghiên cứu viên có thể đúng chuyên ngành hay khác chuyên ngành nhưng có điều kiện được nghiên cứu về quản lý môi trường chiếm tỷ lệ 47,9\%; trong đó có tới $52,1 \%$ các nghiên cứu viên có điều kiện nghiên cứu về kỹ thuật, công nghệ môi trường qua các chương trình, dự án, đề án, phòng thí nghiệm cụ thể. Các nghiên cứu viên tuy ít được bổ sung phần bồi dưỡng kiến thức qua trường đào tạo, nhưng kiến thức thực tiễn được bổ sung thường xuyên, tính thời sự của vấn đề môi trường vì thế cũng được cập nhật. Tuy nhiên, rất ít số nghiên cứu viên này có tham gia đào tạo, hướng dẫn sinh viên cụ thể, do các trường đào tạo không chính thức liên kết giữa đào tạo và thí nghiệm, chủ yếu các nghiên cứu viên hướng dẫn, đào tạo trực tiếp cán bộ tại chính cơ sở đó và do mối quan hệ không chính thức. Vì thế, lượng học viên được đào tạo với đội ngũ này so với tổng lượng sinh viên được đào tạo chiếm tỷ lệ rất nhỏ $(5,1 \%)$.

\section{7. Đối tượng được đào tạo}

Đối tượng đào tạo ngày càng được mở rộng ở nhiều lĩnh vực khác nhau và cùng hướng về mục tiêu có bằng cấp về môi trường và có thể làm ngành môi trường.

Bảng 2. Tỷ lệ tuoong ưng giũa chuyên ngành và sản phẩm đào tạo theo chuyên ngành (Kết quả điều tra so bộ tù Khoa tài nguyên và môi truờng, Đại học Thái Nguyên, 7/2018)

\begin{tabular}{|c|c|c|c|c|c|c|}
\hline Lĩnh vực đào tạo & $\begin{array}{l}\text { Quản lý } \\
\text { môi } \\
\text { trường }\end{array}$ & $\begin{array}{l}\text { Công nghệ } \\
\text { môi trường }\end{array}$ & $\begin{array}{l}\text { Thổ nhưỡng } \\
\text { và môi trường } \\
\text { đất }\end{array}$ & $\begin{array}{l}\text { Sinh } \\
\text { thái }\end{array}$ & $\begin{array}{l}\text { Bảo vệ, sử dụng } \\
\text { hợp lý tài nguyên } \\
\text { môi trường }\end{array}$ & Khác \\
\hline Chuyên ngành & $41,4 \%$ & $29,2 \%$ & $8,8 \%$ & $13,5 \%$ & $4,1 \%$ & $3 \%$ \\
\hline $\begin{array}{l}\text { Sản phẩm đào tạo } \\
\text { làm theo chuyên } \\
\text { ngành }\end{array}$ & $18,5 \%$ & $21,2 \%$ & $11,1 \%$ & $9,2 \%$ & $2,9 \%$ & $37,1 \%$ \\
\hline $\begin{array}{l}\text { Đánh giá của đơn vị } \\
\text { thụ hưởng sản phẩm } \\
\text { đào tạo }\end{array}$ & $41,2 \%$ & $39,6 \%$ & $32,1 \%$ & $45 \%$ & $37,9 \%$ & $11,2 \%$ \\
\hline
\end{tabular}

Kết quả điều tra cho thấy, số lượng người được đào tạo theo nhiều chuyên ngành khác nhau, khi tốt nghiệp đi làm theo các chuyên ngành cũng khác nhau nhưng tỷ lệ làm không đúng ngành chiếm tỷ lệ cao. Họ tham gia nhiều lĩnh vực khác chuyên ngành (chiếm 37,1\%). Trong số những người được đào tạo đi làm được các cơ sở hay doanh nghiệp đánh giá đạt yêu cầu thấp, thường dưới $50 \%$ và có lĩnh vực khác khi triển khai chuyên sâu môi trường chỉ đạt chất lượng 11,2\%. Nhiều người sau đào tạo không được doanh nghiệp chấp thuận, hoặc chính bản thân họ không chủ động và tự tin làm việc. Điều này cho thấy việc đào tạo và chất lượng đào tạo, nhu cầu từ thực tiễn của các cơ sở và doanh nghiệp chưa đồng bộ. Vì thế đào tạo ra nhưng chất lượng không đảm bảo hoặc phải làm trái ngành.
Theo đánh giá từ phía đối tượng được đào tạo, họ học lý thuyết nhiều, trừu tượng $(87,2 \%$ thời lượng học); họ được đào tạo thụ động, có được thí nghiệm thực hành nhưng thời lượng ít (2,1\% thời lượng).

Một số trường, sinh viên được trải nghiệm thực tiễn nhưng không nhiều, các trường không chuyên ngành rất hạn chế phần thực tiễn.

Trong đợt kiểm tra đánh giá chất lượng đầu ra của khoa tài nguyên và môi trường, trường đại học khoa học, đại học Thái Nguyên tổ chức tháng $5 / 2017$ về đào tạo chuyên ngành môi trường cho thấy $41,2 \%$ các sinh viên chuẩn bị tốt nghiệp không nắm được các kiến thức cơ bản về môi trường và đặc biệt học bộ môn nào thì chuyên về bộ môn đó, thiếu kiến thức tổng hợp, bao trùm về môi trường. Đây là vấn đề cần xem 
xét trong tổng thể công tác đào tạo.

\subsection{Giải pháp đề xuất}

Qua nghiên cứu chung về hệ thống cán bộ, các trường đào tạo, chất lượng giáo viên, giảng viên và đối tượng đào tạo, bức tranh tổng thể về thực trạng được thể hiện, có thể phân tích và so sánh trong hệ thống để đề xuất ra giải pháp cụ thể.

\section{* Đối với đào tạo chuyên ngành}

- Cần có quy hoạch các trường, cơ sở đào tạo một cách hệ thống, thống nhất.

- Có sự kết hợp, phối hợp giữa cơ sở sản xuất, doanh nghiệp với các cơ sở đào tạo.

- Cần có sự kết hợp giữa cơ sở đào tạo với các cơ sở nghiên cứu nhằm gắn kết giữa đào tạo và thực tiễn.

- Có kế hoạch đào tạo, bồi dưỡng hàng năm đối với giáo viên, giảng viên và nghiên cứu viên.

- Cải tiến cách tiếp cận lấy người học làm trung tâm mà phải lấy nội dung đào tạo làm trung tâm;

- Các trường nên liên kết hệ thống để có thể chia sẻ kinh nghiệm và đào tạo đạt chất lượng đối với tất cả sản phẩm đầu ra của các trường.

- Nhà nước, các đơn vị, cơ quan có chính sách khuyến khích, thu hút nhân tài; xây dựng các chế độ, chính sách đãi ngộ trong đào tạo, phát triển nguồn nhân lực.

- Đào tạo đội ngũ chuyên gia, cán bộ khoa học cải tiến nội dung lý thuyết và thực hành, khung chương trình, nội dung giảng dạy, cân đối giữa lý thuyết và thực hành (trên cơ sở phân tích số liệu và điều tra nhanh thực trạng).

- Trong đào tạo môi trường có thể phân nhiều chuyên ngành, tuy nhiên tính bao quát, tổng thể phải có trong nội dung đào tạo của tất cả các chuyên ngành, đó là đặc thù của đào tạo chuyên ngành môi trường.

- Hệ thống trường đào tạo, bồi dưỡng cần có kế và công nghệ có năng lực chuyên môn sâu, có kỹ năng nghiên cứu, tiếp thu công nghệ cao, hiện đại, triển khai chuyên nghiệp theo chuẩn quốc tế; bồi dưỡng về chuyên môn nghiệp vụ, kiến thức, kỹ năng quản lý khoa học và công nghệ, quản lý đổi mới sáng tạo nhằm nâng cao trình độ chuyên môn, nghiệp vụ, kiến thức, kỹ năng nghiên cứu và triển khai đối với đội ngũ chuyên gia, cán bộ khoa học và công nghệ để hình thành lực lượng cán bộ có trình độ cao nhằm triển khai có hiệu quả các nhiệm vụ quan trọng, vĩ mô thuộc ngành, lĩnh vực.

- Huy động nguồn lực triển khai

* Đối với với đào tạo bồi dương

- Đối tượng đào tạo, bồi dưỡng là các cá nhân được quy hoạch các chức danh chuyên gia, cán bộ khoa học và công nghệ hoặc có yêu cầu nghiên cứu chuyên sâu về lĩnh vực chuyên môn thuộc các lĩnh vực ưu tiên, trọng điểm hoặc có kế hoạch nghiên cứu, triển khai các nhiệm vụ nghiên cứu khoa học và công nghệ trong ngành, lĩnh vực đang thực hiện hoặc đang chủ trì thực hiện các nhiệm vụ cấp quốc gia, nhiệm vụ đặc biệt khác; có trình độ ngoại ngữ đáp ứng yêu cầu.

- Hình thức đào tạo: đào tạo theo phương thức phối hợp toàn thời gian ở nước ngoài; kết hợp trong nước với nước ngoài hoặc toàn thời gian trong nước (có mời chuyên gia nước ngoài về đào tạo). Đào tạo thông qua việc triển khai các nhiệm vụ khoa học.

\section{Kết luận}

Đội ngũ chuyên gia, cán bộ khoa học và công nghệ là nhân tố quyết định sự phát triển khoa học và công nghệ, là khâu đột phá trong phát triển nhân lực ngành tài nguyên và môi trường. Đào tạo, phát triển đội ngũ chuyên gia, cán bộ khoa học và công nghệ gắn kết chặt chẽ với thu hút và sử dụng, có sự phối hợp đồng bộ giữa các cơ quan, đơn vị trong và ngoài Bộ Tài nguyên và Môi trường; đa dạng hóa các nguồn lực đầu tư cho đào tạo, bồi dưỡng, thu hút sử dụng đội ngũ chuyên gia, cán bộ khoa học và công nghệ. Xác định cụ thể đối tượng, xây dựng kế hoạch đào tạo, bồi dưỡng khả thi, hiệu quả theo từng giai đoạn để đào tạo, phát triển đội ngũ chuyên gia, cán bộ lĩnh vực môi trường. 


\title{
Tài liệu tham khảo
}

1. Bộ Tài nguyên và Môi trường (2015), Đề xuất các giải pháp đột phá tăng cuờng công tác quản lý nhà nước về bảo vệ môi truò̀ng trong giai đoạn 2016-2020, Hưng Nam, http://www.monre.gov.vn.

2. Lê Huy Bá (2016), Quản lý môi trường - Phần chuyên đề, NXB Đại học quốc gia Thành phố Hồ Chí Minh.

3. Nguyễn Thị Vân Hà (2007), Quản lý chất lượng môi trường, NXB Đại học quốc gia Thành phố Hồ Chí Minh.

4. Lưu Đức Hải (2013), Cẩm nang Quản lý môi trường, NXB Giáo dục Việt Nam.

5. Lưu Đức Hải và Nguyễn Ngọc Sinh (2001), Quản lý môi trường cho sự phát triển bền vũ̃ng, NXB Đại học quốc gia Hà Nội.

6. Nguyễn Hằng (2015), Tăng cường công tác quản lý nhà nước về môi trường, Tạp chí Môi trường, http://tapchimoitruong.vn

7. Nguyễn Thị Nga (2016), Bảo vệ môi trương tụ nhiên ở Việt Nam, Tạp chí Cộng sản, http://www.tapchicongsan.org.vn.

8. Văn Hưu Tập (2016), Mục tiêu co bản của quản lý môi truờng, http://moitruongviet.edu.vn.

9. Văn Hữu Tập (2015), Giải pháp tăng cuờng quản lý nhà nước về bảo vệ môi truờng, http://moitruongviet.edu.vn.

10. Lâm Minh Triết và Huỳnh Thị Thu Hằng (2008), Con người và môi trường, NXB Đại học quốc gia Thành phố Hồ Chí Minh.

\section{SOLUTIONS IN ENHACING QUALITY OF HUMAN RESOUCES ON ENVIROMENT}

\author{
Pham Thi To Oanh ${ }^{1}$ \\ ${ }^{1}$ Vietnam Cooperative Alliance
}

\begin{abstract}
Viet Nam was impacted on climate changing, environmental polution; so it is necessary in supporting human resource to solve problems in central, provincal, county and commune levels. The rate of officers, teachers, facuties, reseachers were trained on environment is small, comparing to total amount. They also lack of practical implementation. Leaners were provided theory knowledge, lack of practice and after they were graduated, their jobs were diffrenrent from specializes. They and training quality were not appreciated effective by companies and enterprises. Most of them could n't adapt on diferent positions. Solutions: devloping on systems of universities, colleges, traning units; combining with demands of enterprises and units; training theories and practices; building capacities of officers, teachers, facuties, reseachers, learners; changing of traning objects from considering learner is destination by considering content is destination; promoting initiatives and creatives; giving policies to attracting tallents.
\end{abstract}

Keywords: Human resources, training, quality on environment. 